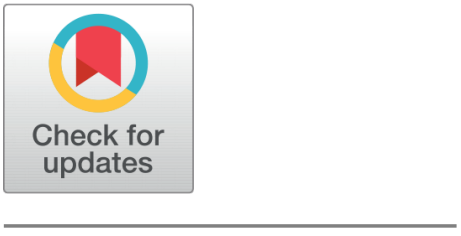

open ACCESS

Received: 22.12 .2020

Accepted: 23.02.2021

Published: 27.04 .2021

Citation: Mariani MJP, Wacas RU, Padre RJ, Soriano GT, Elveña VB, Sarne JC (2021) Design modification of a cost-efficient microcontroller-based egg incubator. Indian Journal of Science and Technology 14(14): 1160-1167. https://doi.org/ 10.17485/IJST/v14i14.2289

* Corresponding author.

Tel: +639171138690

mpmariani@ksu.edu.ph

Funding: None

Competing Interests: None

Copyright: ( 2021 Mariani et al. This is an open access article distributed under the terms of the Creative Commons Attribution License, which permits unrestricted use, distribution, and reproduction in any medium, provided the original author and source are credited.

Published By Indian Society for Education and Environment (iSee)

ISSN

Print: 0974-6846

Electronic: 0974-5645

\section{Design modification of a cost-efficient microcontroller-based egg incubator}

\author{
Mathew Jun P Mariani ${ }^{1}{ }^{*}$, Ronald U Wacas ${ }^{1}$, Rafael J Padre ${ }^{2}$, Gerlie T Soriano ${ }^{1}$, \\ Venus B Elveña ${ }^{1}$, Jayhan C Sarne ${ }^{1}$
}

1 Kalinga State University, Tel.: +639171138690

2 Isabela State University

\section{Abstract}

Objectives: This study is geared towards the design modification of a costefficient automated egg incubator. Methods: To meet the objectives, the researchers conducted several document analyses relative to the study to establish further the requirements needed to design a microcontroller-based incubator. Interviews with the farmers from the Northern Luzon Philippines also contributed to the design modification's success. The researchers gathered information on temperature, humidity, cost-efficiency, advantages and disadvantages of the existing incubators, and the farmers' feedback before designing. The incubator designed in this study uses modern methods such as the automated controllable device, which maintains humidity \& temperature and enables automatic tray switching; The study has also discussed the hatching efficiency and hatching capacity; a financial review between the previous egg incubator and the proposed microcontroller egg incubator has been done. Findings: The study showed that the designed incubator's hatching efficiency ranges from $80-93 \%$ and with an average of $86.5 \%$ with the number of hatched eggs was 56 (93\%) duck eggs and 48 (80\%) chicken eggs. It also shows that duck eggs have the most number of hatching compared to chicken eggs. It also showed higher net income for the farmers. Further, the Modified technology is cost-efficient than the manual, which indicates a lower cost per chicken and ducks egg incubation of Php 20.07 and Php 17.2. Novelty/Improvement: The study demonstrated that the microcontrollerbased egg incubator is commendable for small-scale poultry producers.

Keywords: Incubator; Microcontroller; Eggs

\section{Introduction}

A relatively large gross domestic product comes from the poultry industry to produce eggs, meat, and feathers. This trade relies much on its output quality and the amount produced yearly ${ }^{(1)}$. In Developed countries, poultry plays a vital role. The commodity is relatively cheap and readily available. In the least developing countries, the projected rise in egg intake from 2005 and 2015 is $26 \%$, compared to just $2.4 \%$ in the more developed economies $^{(2)}$. 
Records from the Philippine Statistic Authority cited that In the Philippines last From October to December 2018, the amount of chicken egg production was 138.54 thousand metric tons. It improved by 8.41 percent relative to the previous year's production of 127.79 thousand metric tons. The production of chicken eggs has recovered from a fall of 0.89 percent in 2016 and 8.41 percent growth in 2018 over the last three years. Increases in chicken egg production were noted in all regions in the fourth quarter of 2018, except Central Luzon, where production levels decreased by 1.19 percent relative to the same period in the previous year ${ }^{(3)}$.

Meeting the high demand for poultry goods includes the use of hatcheries for artificial eggs. However, the backyard and small-scale poultry farmers are constrained by their dependence on natural incubation/commercial hatcheries. Besides, the number of chicks produced through natural incubation is meager due to irregular environmental parameters like temperature, humidity, and hen's death, leading to the total collapse of this incubation process ${ }^{(4)}{ }^{(5)}$.

Four aspects established major significance in incubating eggs artificially: temperature, humidity, ventilation, and rotation. Temperature is the most critical element. Humidity appears to be ignored, though, which triggers specific difficulties with hatching. The comprehensive analysis showed that when the relative humidity is $60 \%$, the optimum incubator temperature is $100^{\circ} \mathrm{F}$. Oxygen concentrations are predicted to be above $20 \%$, carbon dioxide is expected to be below $0.5 \%$, and 12 cubic feet per minute of the passage of air past the egg is expected to occur ${ }^{(6)}$.

The benefits of artificial incubation are as follows: (1) quantity of chicks that may be hatched in a short time; (2) the probability of preparing when to hatch chicks, as opposed to a hen where it may not be understood when to sit for eggs; (3) the failure to transmit parasites and diseases to chicks; (4) the lack of expense to feed the brooded hen as the incubator is used; (5) the decreased risk of egg spoilage when all eggs experience optimum hatching temperatures; and, (6) The lack of chances of hen destroying eggs by pecking, a normal phenomenon with natural incubation. There are, on the other hand, several risks. Which included (1) the high price of the incubator, as most incubators are highly-priced and not economical for small-scale farmers; (3) the need for expertise to handle and operate the incubator; and (4) the high risk of destroying the embryo, which may also cause eggs to break especially during egg rotation.

According to ${ }^{(7)}$, the method of incubation of poultry eggs has advanced over the years as a result of scientific and technical advances. At present, the key direction of research is to regulate eggshells' temperature by integrating the results of variables influencing incubation. Further, Light monitoring is vital to ensure the reliability of the egg hatching process. Automated incubation is already used in poultry farms for the hatching of eggs ${ }^{(8,9)}$. The temperature and humidity must be controlled correctly to help hatch the eggs, which is one of the primary purposes of a microcontroller-based egg incubator ${ }^{(8)}$.

In the automation, monitoring the parameters provided the appropriate conditions equally, and in the management of those parameters, the egg-turning process helped increase the artificial hatching and provided the same treatment as the layer fowl. Here, the volume of eggs hatching at a time is increased. It gives rise to the number of pullets ${ }^{(10)}$.

The research's primary purpose is to conduct a design modification and cost-efficiency performance of a microcontrollerbased incubator appropriate for the province's socio-economic setting, where small rural farmers cannot afford the costly equipment. This locally available technology is expected to contribute much to the development of the poultry industry. The microcontroller-based incubation system's importance is a cost-efficient and relevant improvement in poultry chicks' production capacity.

Develop a cost-efficient microcontroller-based egg incubator suitable for small-scale consumption of locally produced poultry, which is low due to materials' insufficiency in developing egg incubator.

Farmers use the manual incubator that was developed by the Department of Agricultural Engineering of Kalinga State University and observed that the manual process of incubation results in the following issues: (1) strict monitoring of temperature humidity, which is time-consuming; and (2) manual switching of the egg which is considered laborious.

This study is geared towards the design modification of a cost-efficient automated egg incubator. Specifically, it is intended to provide an incubator design that uses modern methods such as the automated controllable device, which maintains humidity $\&$ temperature and enables automatic tray switching.

\section{Materials and Method}

The materials that were used in the study are the following: Arduino Uno R3, AT Mega 328 Microcontroller, DHT11 (Temperature and Humidity) ${ }^{(9)}$, Relay Switch, Incandescent Bulb, Motor, and Fan.

\section{Data Gathering}

The researchers conducted several document analyses relative to the study to establish further the requirements needed to design a microcontroller-based incubator. Interviews with the farmers also contributed to the success of the design modification. 
The researchers gathered information on temperature, humidity, cost-efficiency, advantages and disadvantages of incubators, and the farmers' feedback. As to feedback, the questions were shown in Table 1.

Table 1. Questions during the interview of the Farmers

How was the egg incubator?
What are the positive and negative impacts of the incubator?
What are the possible issues that came out during the process of incubation?
How can we further improve the egg incubator?

Schematic Diagram:

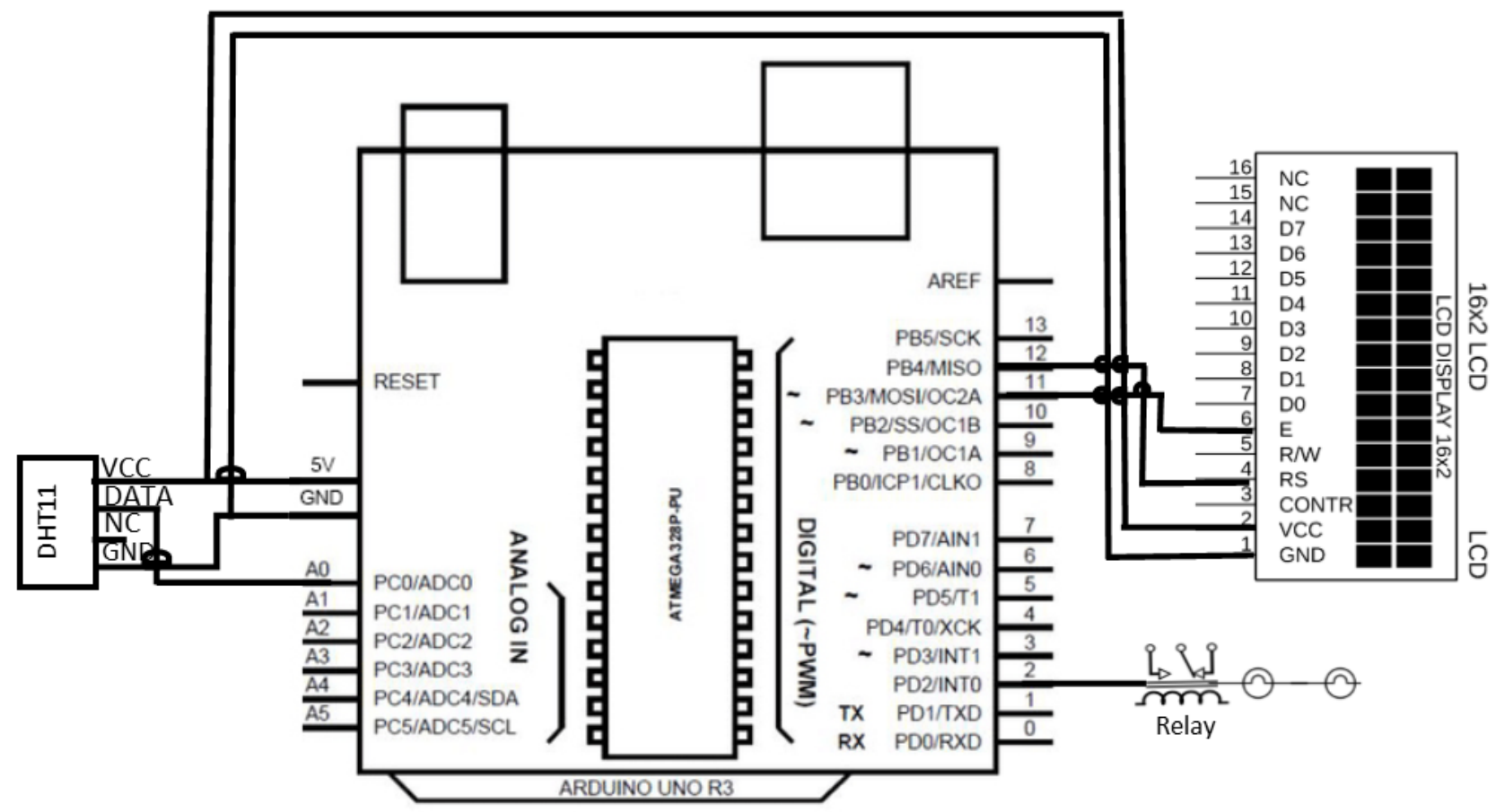

Fig 1. Schematic Diagram

The diagram indicates that the DHT 11 sensor is attached to the Arduino Uno analog pin 1. The DHT 11 sensor captures both temperature and humidity in an analog format and transforms the microcontroller to degrees Celsius. It has a relay switch attached to the optical pin two that will be activated any time the threshold value is reached. This will act as a control switch for the two incandescent bulbs preserving the appropriate temperature. The $16 \mathrm{x}$ 2LCD module attached to the 1,3,4,5,6,7,11,12 optical pin shows the current temperature and humidity.

Conversion of Analog Value from DHT11 to Degrees Celsius:

- Formula:

$$
\begin{aligned}
& Y=Z \times 5 \\
& Y=(Z \times 5) / 1024 \\
& X=(Y-0.5) \times 100
\end{aligned}
$$

- Where:

$X$ is Temperature in Degrees Celsius

$Y$ is voltage in $m V$

$Z$ is Analog Value from DHT11 Sensor 


\section{PARAMETERS}

$$
\text { Hatching Efficiency }(\%)=\frac{\text { Number of eggs hatched }}{\text { Number of incubated fertile eggs }} \times 100 \%
$$

Electricity consumption formula

Wattage $x$ operating time per day $x$ incubation days $x$ electric cost per $k w-h r=$ electricity consumption

Revenue

Hatching efficiency $x$ unit price per chicks $x$ No. of operations per year $=$ revenue

Cost-Effectiveness

$$
\frac{\text { Cost during incubation }}{\text { Outcome }(\text { total number of eggs hatched })}=\text { Cost }- \text { effectiveness }
$$

\section{Results and Discussion}

\section{Design Modification}

The following criteria were considered in modifying a cost-efficient Microcontroller-based egg incubator: simple design, microcontroller-based, the capacity of 64 eggs, easy to operate and requires less maintenance, made out of locally available materials and components, and tray/cabinet-type incubating chamber.

\section{Dimension and microcontroller of the Incubator}

A Microcontroller-based egg incubator with a capacity of 64 eggs was designed based on facts and information gathered from research about egg incubation. The incubator has a box body, egg tray, Arduino Uno R3, AT Mega 328 Microcontroller, DHT11 (Temperature and Humidity) ${ }^{(9)}{ }^{(10)}$, relay switch, Incandescent bulb, motor, fan. The incubator dimension was 25 inches in length, 20 inches in width, and 24 inches in height. The frame was built from plywood, while the egg tray and flooring were constructed from wood. The door was made out of plywood and a glass at the center.

The main controller of the system used Arduino Uno with ATMega 328 microcontroller. The program to control the effectors (relay switch, motor) was written in $\mathrm{C}++$ language and was then compiled into an executable file using Arduino IDE.

Arduino Uno is an ATmega328 based microcontroller board. It is an open-source prototyping tool, and its simplicity makes it suitable for hobbyists and professionals alike. The Arduino Uno has 14 optical input/output pins (6 of which can be used as PWM outputs), 6 analog inputs, a $16 \mathrm{MHz}$ crystal oscillator, a USB connection, a power jack, an ICSP header, and a reset button.It contains everything you need to help a microcontroller; link it to a device with a USB cable or power it with an ACto-DC adapter or battery to get started. Figure 2 displays Arduino UNO R3 and the details as seen in Table 2.

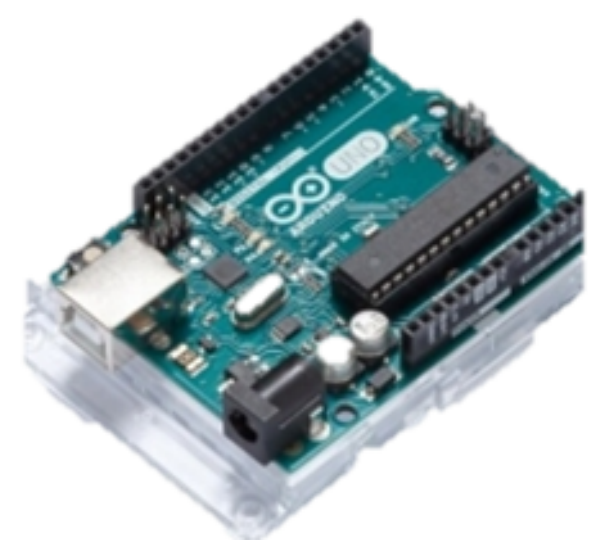

Fig 2. Arduino Uno R3 
Table 2. Arduino Uno R3 Specification

\begin{tabular}{ll}
\hline Arduino Uno R3 Specification & \\
\hline Microcontroller & ATmega328v \\
Operating Voltage & $5 \mathrm{~V}$ \\
Input Voltage (recommended) & $7-12 \mathrm{~V}$ \\
Input Voltage (limits)v & $6-20 \mathrm{~V}$ \\
Digital I/O Pins & 14 (of which 6 provide PWM output) \\
Analog Input Pins & 6 \\
DC Current per I/O Pin & $40 \mathrm{~mA}$ \\
DC Current for 3.3V Pin & $50 \mathrm{~mA}$ \\
Flash Memory & $32 \mathrm{~KB}$ of which 0.5 KB used by bootloader \\
SRAM & $2 \mathrm{~KB}$ (ATmega328) \\
EEPROM & $1 \mathrm{~KB}$ (ATmega328) \\
Clock Speed & $16 \mathrm{MHz}$ \\
\hline
\end{tabular}

\section{Egg Turning}

The egg turner rotated the eggs $90^{\circ}$ inclination and moved in axial rotation. Egg turning stops the embryo from being bound to extra-embryo membranes, decreases the risk of embryo death, and insalubrious hatching ${ }^{(10)}$. In order to ensure proper and timely hatch, the egg should be turned at least five times a day ${ }^{(8)}(9)$.

\section{Temperature, Humidity, Water loss, and Ventilation of Air}

In this research, the sensor used to monitor both temperature and humidity within the incubator is DHT11, as seen in Figure 3 ; it is a low-cost sensor consisting of a capacitive humidity sensor and a thermistor that monitors the surrounding air and outputs a digital signal to the data pins. The digital signal value captured from DHT11 is then translated to Degree Celsius ${ }^{(11)}$. Table 3 shows the specifications of DHT11.

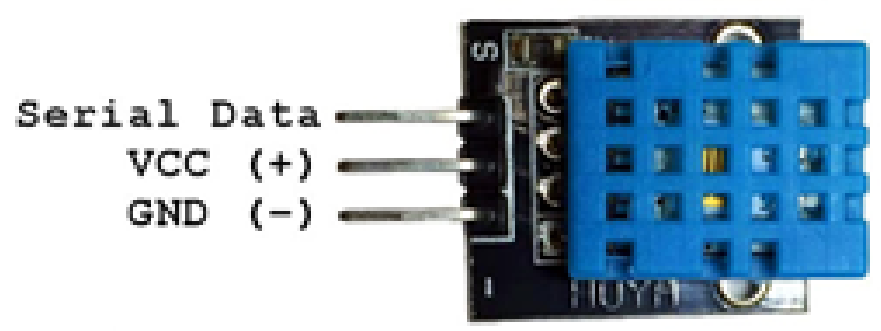

Fig 3. HT 11 (Temperature and Humidity Sensor)

Table 3. HT11 Specification

\begin{tabular}{|c|c|}
\hline PCB size & $22.0 \mathrm{~mm}$ X $20.5 \mathrm{~mm} \mathrm{X} 1.6 \mathrm{~mm}$ \\
\hline Working voltage & 3.3 or $5 \mathrm{~V} \mathrm{DC}$ \\
\hline Operating voltage & 3.3 or $5 \mathrm{~V} \mathrm{DC}$ \\
\hline Measurement range & $20-95 \% \mathrm{RH} ; 0-50^{\circ} \mathrm{C}$ \\
\hline Resolution & 8bit(temperature),8bit(humidity) \\
\hline Compatible interfaces & 2.54 3-pin interface and 4-pin Grove interface(1) \\
\hline
\end{tabular}

Two 25-watt bulbs provided the heating system of the incubator. Inside the incubator, the temperature should range from 36 to $38^{\circ} \mathrm{C}$. If the temperature falls below $36^{\circ} \mathrm{C}$, the relay switch will automatically turn on. If it is above $38^{\circ} \mathrm{C}$, the effectors will turn off. The state of the conditions, such as the actual temperature and humidity environment, is seen on the Arduino board's LCD screen ${ }^{(9)}$. The pc fan served as the distributor of heat inside the incubator. It also maintained the oxygen needed while the water fan maintained the required humidity inside the incubator. Tables 4 and 5 show the sensor parameters of humidity and 
temperature.

Table 4. Humidity Sensor Parameter

\begin{tabular}{llllll}
\cline { 1 - 3 } Parameter & Min. & Typical & Max. & Unit \\
\cline { 1 - 3 } Accuracy $\left(25^{\circ} \mathrm{C}\right)$ & - & \pm 4 & & $\% \mathrm{RH}$ \\
Accuracy $\left(0-50^{\circ} \mathrm{C}\right)$ & - & - & \pm 5 & $\% \mathrm{RH}$ \\
Measurement range $\left(25^{\circ} \mathrm{C}\right)$ & 20 & - & 95 & $\% \mathrm{RH}$ \\
Response time: $1 / \mathrm{e}(63 \%) 25^{\circ} \mathrm{C}, 1 \mathrm{~m} / \mathrm{s}$ air & 6 & 10 & 15 & \\
\hline
\end{tabular}

Table 5. Temperature Sensor Parameter

\begin{tabular}{lllll}
\hline Parameter & Min. & Typical & Max. & Unit \\
\cline { 1 - 4 } Accuracy & \pm 1 & - & \pm 2 & ${ }^{\circ} \mathrm{C}$ \\
Measurement range & 0 & - & 50 & ${ }^{\circ} \mathrm{C}$ \\
Response time /e( (63\%) & 6 & & 30 & \\
\hline
\end{tabular}

\section{Hatching Efficiency}

It was shown in Table 6 that duck eggs and chicken eggs vary in the number of fertile eggs and the number of hatched eggs. There were 60 or $100 \%$ fertile chicken eggs and 60 or $100 \%$ duck fertile eggs. The number of hatched eggs was 56 (93\%) and 48 $(80 \%)$.

Table 6. Hatching Efficiency (\%)

\begin{tabular}{llll}
\hline Egg type & Number of fertile eggs & Number of hatched eggs & Hatching efficiency (\%) \\
\hline Duck & 60 & 56 & 93 \\
Chicken & 60 & 48 & 80 \\
\hline
\end{tabular}

It was found out that the incubator's hatching efficiency ranges from $80-93 \%$ and with an average of $86.5 \%$. The study of Sunday et al. also revealed the following acceptable and significant results: 95 fertile eggs, 85 hatched eggs, and 89,47 percent hatchability ${ }^{(12)}$. According to the Sanjaya et al. in their study Quail Eggs Smart Incubator, show the best result to hatching the quail egg and get the result that by 490 eggs, $87.55 \%$ successfully normally hatch, $0.41 \%$ hatch but defective, and $1.84 \%$ hatch but dead, and $10.20 \%$ do not hatch yet on 17 th days incubate period ${ }^{(13)}$. Further, the Automated egg incubator model has been found to be very much improved in terms of efficiency of hatchability, less human monitoring, and problems associated with manual egg rotation in previous versions ${ }^{(14)}$.

\section{Hatching Capacity}

Table 7 shows that the incubator's hatching capacity was 56 eggs for duck and 48 eggs for chicken, and with an average of 52 eggs. These show that duck eggs have the most number of hatch eggs compared to chicken eggs. Our results in in-tune with the earlier report, which concluded that the locally manufactured automated electrical egg incubator was found to be accurate, as the output test carried out resulted in an average hatchability of $84.06 \%{ }^{(15)}$.

Table 7. Hatching Capacity

\begin{tabular}{lll}
\hline Treatment & Number of fertile eggs & Number of hatched eggs \\
\hline 1. Duck & 60 & 56 \\
2. Chicken & 60 & 48 \\
\hline
\end{tabular}

\section{Financial Analysis}

Table 8 Indicates that based on the hatched chicks, the Manual egg incubator net income per year is Php14,300 compared to the Microcontroller-based egg incubator with a net income of Php 22,970 per year, which means that the Modified technology is cost-efficient than the manual. 
Table 8. Financial Analysis on Chicks

\begin{tabular}{lll}
\hline & Modified & Manual \\
\hline Cost & & \\
Additional Materials & 1330.00 & N/A \\
Electricity & $1200.00 /$ year & $1200.00 /$ year \\
Labour & N/A & $10,000.00 /$ year \\
& & \\
Sub-total & 2530.00 & $11,200.00$ \\
Revenue & $25,500 /$ year & $25,500 /$ year \\
Net Income & $22,970.00 /$ year & $14,300 /$ year \\
\hline
\end{tabular}

Table 9 Indicates that based on the hatched ducklings, the Manual egg incubator net income per year is Php 14,178 compared to the Microcontroller-based egg incubator with a net income of Php22,348 per year, which means that the Modified technology is cost-efficient than the manual.

Table 9. Financial Analysis of Ducklings

\begin{tabular}{lll}
\hline & Modified & Manual \\
\hline Cost & 1330.00 & N/A \\
Additional Materials & $1322.00 /$ year & $1322.00 /$ year \\
Electricity & N/A & $10,000.00 /$ year \\
Labour & 2652.00 & $11,322.00$ \\
Sub-total & & \\
Revenue & $25,500 /$ year & $25,500 /$ year \\
Net Income & $22,348.00 /$ year & $14,178 /$ year \\
\hline
\end{tabular}

\section{Cost-Effectiveness Analysis}

The study showed that when it comes to cost-effectiveness, the microcontroller-based incubator indicates a significantly lower cost per chick and duckling during the 9 batches of incubation, Php 5.86 and Php 5.26, respectively. In comparison, the manual incubator cost per chick and duckling are Php 25.93 and Php 22.46, respectively.

\section{Conclusion}

The microcontroller-based egg incubator was designed and constructed to give better poultry production for small-scale or for rural farmers. This study concludes that poultry producers scaled-up the production without continuous monitoring and will lessen possible developmental growth problems that natural incubation causes. The integrated small-scale singlemicrocontroller device streamlined the temperature control unit's development and the carefully studied and engineered control of the incandescent lamps and fans. Turning mechanism, a new technical viewpoint is developed for the farmers, incorporating smart farming strategies that are cost-effective at their end. Furthermore, the study demonstrated that the microcontroller-based egg incubator is commendable for small-scale poultry producers.

Further, for future works, the researchers highly recommend modifying the said design into a solar-powered microcontroller-based egg incubator.

\section{References}

1) Deysolong J, Mañalac H, Merto JMR, Mesina E, Teodoro N. Arduino Based Egg Incubator for Anas Luzonica. European Academic Research. 2017;5(8):4527-4546.

2) Farrell D. The role of poultry in human nutrition. In: and others, editor. Poultry Development Review. 2013;p. 1-8. Available from: http://www.fao.org/ 3/i3531e/i3531e.pdf.

3) Chicken Egg Situation Report. 2018. Available from: http://www.psa.gov.ph/content/chicken- egg-situation-report.

4) Kyeremeh F, Peprah F. Design and Construction of an Arduino Microcontroller-based EGG Incubator. International Journal of Computer Applications. 2017;168(1):15-23. Available from: https://dx.doi.org/10.5120/ijca2017914261.

5) Agbo DO, Otengye OJ, Dodo SH. Proposed Development of a Solar Powered AutomatedIncubator for Chickens. International Journal of Engineering and Techniques. 2018;4(1):517-524. Available from: http://oaji.net/articles/2017/1992-1522324316.pdf.

6) Clauer PJ, Animal and Poultry Sciences. Incubating Eggs. Virginia Polytechnic Institute and State University. 2009. Available from: https://www.pubs. ext.vt.edu/content/dam/pubs_ext_vt_edu/2902/2902-1090/2902-1090_pdf.pdf. 
7) Adamu N, Olabode O, Florence S, Martins A, Mercy A. Low-Cost Design of Poultry Egg Incubator with W1209 Digital Temperature Controller. International Journal for Academic Engineering Research. 2020;4(4):50-55. Available from: https://www.academia.edu/42931484/Low_Cost_Design_of_ Poultry_Egg_Incubator_with_W1209_Digital_Temperature_Controller.

8) Sruthi M, Jayanthy B, S. Development of Cloud Based Incubator Monitoring System using Raspberry Pi. International Journal of Education and Management Engineering. 2017;5:35-44. Available from: https://doi.org/10.5815/ijeme.2017.05.04.

9) Aldair AA, Rashid AT, Mokayef M. Design and Implementation of Intelligent Control System for Egg Incubator Based on IoT Technology. In: 4th International Conference on Electrical, Electronics and System Engineering. 2018;p. 49-54. doi:10.1109/ICEESE.2018.8703539.

10) Thomas DA, Reji C, Joys J, Jose S. Automated Poultry Farm with Microcontroller based Parameter Monitoring System and Conveyor Mechanism. In: 2020 4th International Conference on Intelligent Computing and Control Systems (ICICCS). 2020;p. 639-643.

11) . 2019. Available from: https://esp8266-shop.com/sensors/measure-temperature-and-humidity-with-dht22-and-esp8266/\#: :text=The\%20DHT22\% 20 is $\% 20$ a $\% 20$ basic.

12) Sunday AA, Ogunbode OA, Babatunde EG, Olalekan AM. Design And Construction Of Automated Eggs Incubator For Small Scale Poultry Farmers. International Journal of Technical Research \& Science. 2020;5(8):1-9. Available from: https://dx.doi.org/10.30780/ijtrs.v05.i08.001.

13) Sanjaya WSM, Maryanti S, Wardoyo C, Anggraeni D, Aziz MA, Marlina L. The development of quail eggs smart incubator for hatching system based on microcontroller and Internet of Things (IoT. 2018 International Conference on Information and Communications Technology (ICOIACT). $2018 ; \mathrm{p} .407-411$. Available from: https://doi.org/10.1109/icoiact.2018.8350682.

14) Agboola AK, Olaniyi OM, Aliyu SO, Ayanwale BA. Increasing Livestock Production in Nigeria: Development of Cost-Effective Models for Bird-Egg Incubator. International Journal of Emerging Technology and Advanced Engineering. 2013;3(3):707-716.

15) Adegbulugbe TA, Atere AO, Fasanmi OG. Development of an Automatic Electric Egg Incubator. International Journal of Scientific \& Engineering Research. 2013;4(9):914-918. 